\title{
Cuidado de la salud mental de las enfermeras: prioridad en la pandemia por la covid-19
}

\author{
Nurses" Mental Health Care: Priority in the Covid-19 Pandemic \\ Cuidado da saúde mental das enfermeiras: prioridade na pandemia \\ pela covid-19
}

Liliana Villarraga de Ramírez'

PALABRAS CLAVE (FuENTE: DeCS)

Enfermeras y enfermeros; salud mental; cuidado de enfermería; infecciones por coronavirus; enfermería.

KEYWORDS (SOURCE: DeCS)

Nurses; mental health; nursing care; coronavirus infections; nursing.

PALAVRAS-CHAVE (Fonte: DeCS)

Enfermeiras e enfermeiros; saúde mental; cuidados de enfermagem; infecções por coronavirus; enfermagem.

DOI: 10.5294/aqui.2021.21.3.1

Para citar este editorial / To reference this editorial / Para citar este editorial

Villarraga-Ramírez L. Cuidado de la salud mental de las enfermeras: prioridad en la pandemia por la covid-19. Aquichan. 2021;21(3):e2131. DOI: https://doi.org/10.5294/ aqui.2021.21.3.1

$1 \bowtie$ https://orcid.org/0000-0003-3710-990x. Universidad Nacional de Colombia, Facultad de Enfermería, Bogotá (Colombia). Ivillarraga@unal.edu.co 
En tiempos de pandemia, la salud física y las consecuencias clínicas de la infección viral son la preocupación esencial; no obstante, también se debe tener en cuenta el impacto sobre la salud mental. De acuerdo con Frawley et al. (2020): "específicamente la relacionada con la angustia moral" derivada de la presión psicológica que experimentan las enfermeras, lo cual constituye el motivo especial de este escrito (1).

Tanto la Ley 1616 del 2013 del Ministerio de Salud de Colombia (2), como la Organización Mundial de la Salud (OMS), definen la salud mental como un saber autónomo de bien-estar. Es indispensable que las personas conozcan sus propias capacidades para afrontar la vida, siendo conscientes de sí mismos y de ser productivos para la comunidad. Actualmente, la salud mental es imperativa frente a la pandemia por la covid-19.

"El campo de la salud mental es complejo y transdisciplinario, admite la comprensión de la subjetividad, la singularidad y la diferencia entre lo individual y lo colectivo; incluye el conflicto en el devenir cotidiano de las instituciones y de la sociedad, abre la mirada hacia la vida social y advierte sus interrelaciones saludables y perjudiciales." (3)

Con estos conceptos las enfermeras de la salud mental abordamos el afrontamiento de la pandemia por la covid 19.

Es inevitable que al despertar, en cada amanecer, nos encontremos con una novedad relacionada con la pandemia a la cual aún no nos acostumbramos, ¿Cómo es que llegamos a una pandemia? ¿A un confinamiento por meses y años?, ¿cómo llegó a ser mundial esta infección?, ¿cuántas mutaciones de un virus se han generado?, ¿Cuántas variedades nos sorprenderán? Röhr S. et al., (2020) en su artículo Psychosocial Impact of Quarantine Measures During Serious Coronavirus Outbreaks: A Rapid Review, establece la importancia de:

"Recopilar evidencias sobre las consecuencias psicosociales de las medidas de cuarentena en relación con brotes anteriores de coronavirus relevantes. Dos coronavirus graves y brotes asociados ya se han producido en el siglo xxI. El primer brote grave fue el síndrome respiratorio agudo severo SRAS en 2002 y 2003 en el sur de China y treinta países más. En 2012, se identificó el síndrome respiratorio agudo severo coronavirus de Oriente Medio MERS-CoV, la primera aparición se ubicó en Arabia Saudita."(4)

En el mes de diciembre del año 2019 el coronavirus ya se encontraba inundando a la humanidad e infectando a miles de perso- nas. Se insistía en que "el virus no viaja" (5) y que son los viajeros quienes lo transportan por todo el mundo: a Colombia llega en el mes de marzo del 2020.

A todos nos tomó por sorpresa, sin preparación y la pandemia puso en evidencia la precariedad de los sistemas de salud. En el momento en que llegó el virus no se contaba con adecuaciones, equipos, materiales y recurso humano del área de la salud para desplegar una óptima atención e incluso aún se presentan algunas dificultades en la atención. Todos hemos aprendido "mientras caminamos" (5), porque "nadie tiene la verdad" (5). En este sentido, la enfermería en salud mental es un grupo clave dentro de una respuesta integrada ante la covid-19 porque cuenta con mayor información, la cual se basa en sus experiencias cotidianas (1) y que se podrían ver reflejadas en escritos sobre las vivencias de las enfermeras y los enfermeros colombianos durante la pandemia.

En las instituciones de salud el personal de enfermería es insuficiente y muchas(os) han adquirido la infección por el virus; paralelamente se registra un incremento en la sobrecarga laboral y psicológica. El personal de enfermería es el primero en abordar a las personas infectadas quienes se encuentran en riesgo de muerte, atienden a las familias en situaciones críticas e intervienen en el duelo de las personas por los continuos fallecimientos en las instituciones.

La dinámica del duelo que deben abordar las enfermeras pone en evidencia el desconcierto y la incredulidad ante la noticia de "positivo para covid-19" de una persona o varios integrantes de una familia, quienes requieren información para reasegurarse de "la verdad". En ese preciso momento, súbitamente se interrumpe la estabilidad personal por la negación e indignación que expresan las personas para evitar la pérdida del propio control; en efecto, al no contar con defensas para el momento de la noticia inesperada, se dificultará afrontar la pérdida y mantener la cordura. Frecuentemente, este descontrol lo reciben las enfermeras, quienes simultáneamente atienden a la familia que necesita ayuda; para este acompañamiento se requiere tiempo y disposición para la escucha y comprensión de las emociones de las personas en sufrimiento. Ante esta situación, el objetivo de la salud mental es restablecer el equilibrio anterior que tenía la persona y la familia, mediante la comprensión del duelo, el apoyo en el conocimiento de la pérdida por muerte inesperada y la prevención de sentimientos de culpa (5). 
Lo anterior constituye la fuente principal de ansiedad para las enfermeras quienes, a través de sus testimonios, expresan:

"Necesitamos asesoría para la intervención en duelo", ... en el hospital covid donde yo trabajo, diariamente mueren más de tres personas; en mi turno, la intervención la hacía en la calle, donde podía ser agredido, hasta que me dieron un galpón donde ahora yo atiendo a las familias ... frecuentemente se me vienen las lágrimas". "Necesitamos apoyo psicosocial, varios compañeros están incapacitados por depresión, pido a Dios no colapsar", ... "me siento desesperado y quisiera no volver al hospital". "Lloro todos los días a gritos antes de llegar y poder ver a mi familia. Me diagnosticaron estrés postraumático; ahora voy a tratamiento psiquiátrico como prevención para mi salud mental" (6).

"Al respecto las enfermeras irlandesas hablan de "daño moral 0 angustia por los resultados de las acciones o la falta de ellas" que violen la responsabilidad moral o ética (añade Greenberg citado por ellas); ese estrés es un riesgo particular del personal sanitario, podría contribuir al desarrollo de dificultades para la salud mental" (1).

¿Cómo no preocuparnos por la salud mental de las enfermeras? Presentan exceso laboral, sobrecarga emocional y diversas hostilidades como el estigma de personas y familias. "La crisis emocional no la hemos dimensionado aún", enfatiza el psiquiatra psicosocial A. Rodríguez (2020) (5).

Los riesgos para la salud mental se exacerban para toda la población mundial haciéndola vulnerable a síntomas y trastornos físicos, psicosomáticos y mentales. Así, "[...] la pandemia de covid-19 no tiene precedentes y el alcance de los efectos psicosociales actualmente no está claro, la OMS lo evalúa como grave" (4).

De acuerdo con A. Rodríguez (2020) (5), la cuarta ola de la actual pandemia estará relacionada con los trastornos mentales: temor, ansiedad, alimentación, sueño, sentimientos de culpa, cansancio, soledad, estrés y estrés postraumático, angustia, pánico, iniciación y/o aumento del consumo de psicoactivos, alcohol y tranquilizantes, ideación suicida, suicidio y maltrato familiar. Ello sin tener en cuenta secuelas aún no estudiadas, como la aparición de trastornos de memoria, sentimientos paranoides, reactivación de duelos y cambios en las dinámicas familiares.

Con la presente pandemia por la covid-19 se requiere una formación urgente para las enfermeras(os) en temas relacionados con la intervención en crisis de niños, adolescentes, jóvenes, pa- rejas y familias. Así mismo, sobre el apropiado acompañamiento en el duelo a personas, parejas y familias en los momentos de contagio de la enfermedad y la muerte; y también en los temas de acompañamiento físico, emocional y espiritual al moribundo, y en la promoción de la solidaridad social y comunitaria.

Respecto de la acción psicosocial, las instituciones deben contar con grupos de apoyo para abordar la salud física y psicológica del personal de enfermería: "las experiencias en Italia, por ejemplo, apuntan a que el personal sufre síntomas somáticos relacionados con el trabajo, la carga psicológica y el estrés emocional" (1). Los grupos de apoyo son importantes para la liberación de las propias crisis, los duelos y el estrés traumático y postraumático. Esta intervención permitiría la comprensión intelectual del fenómeno y el fortalecimiento de intervenciones de autocuidado y cuidado.

Surge entonces la pregunta: ¿cómo constituirnos en grupo de apoyo y acogimiento para enfermeras en crisis, afrontando el sufrimiento por el contagio y la muerte de sus propios familiares y compañeros? Este momento crucial nos permite ver con claridad las brechas en salud, las inequidades frente a los profesionales y la necesidad de liderar el cambio, así como la necesidad de desarrollar consciencia gremial y elaborar recomendaciones laborales con apoyo jurídico desde una perspectiva de derechos humanos. Es el momento de decir, sentir y pensar "somos un nosotros" (5).

Con apoyo de la Fundación Formarte, la Comisión de Salud Mental de la Asociación Colombiana de Facultades y Escuelas de Enfermería -ACOFAEN- y la Asociación Nacional de Enfermeras de Colombia -ANEC-, se articularon las artes con la enfermería en salud mental, y tomando como referente la teoría de Mishel (2011) (7), en el año 2020 se llevaron a cabo dos encuentros de nueve horas cada uno con enfermeras docentes, de urgencias y de cuidados intensivos, para abordar la incertidumbre que nos rodea y así, promover y prevenir los efectos nocivos para la salud mental.

En el presente año (2021) apoyamos a 40 enfermeras docentes y de servicio en la prevención y promoción de su salud mental; además, se profundizó sobre "la escucha", herramienta esencial para el establecimiento de la empatía.

Recomendamos prepararnos, de manera anticipatoria, para evitar el estigma que se comienza a construir alrededor de la covid-19, así como surgió el estigma sobre el trastorno mental y, hace unos años, sobre el VIH/sida, entre otros. 


\section{Referencias}

1. Frawley T, Van Gelderen F, Somanadhan S, Coveney K, Phelan A, Lynam-Loane P, et al. The impact of COVID-19 on health systems, mental health and the potential for nursing. Ir J Psychol Med. 2020;38(3):220-226. DOI: https://doi. org/10.1017/ipm.2020.105

2. República de Colombia. Ley 1616 del 21 de enero de 2013. "Por medio de la cual se expide la Ley de Salud Mental y se dictan otras disposiciones". [Internet]. [Citado agosto 4 de 2021]. Disponible en: http://www.secretariasenado.gov.co/ senado/basedoc/ley_1616_2013.html

3. Rodríguez JJ (editor) \& Organización Panamericana de la Salud [OPS]. Salud mental en la comunidad [Internet]. $2^{a}$. ed. Washington: OPS. Disponible en: https://iris.paho.org/handle/10665.2/51463

4. Röhr S, Müller F, Jung F, Apfelbacher C, Seidler A, Riedel-Heller SG. Psychosocial Impact of Quarantine Measures During Serious Coronavirus Outbreaks: A Rapid Review. Psychiatr Prax. 2020;47(4):179-189. DOI: https://doi. org/10.1055/a-1159-5562

5. Rodríguez A. (Asociación Colombiana de Facultades y Escuelas de Enfermería -ACOFAEN-). Conversación con: Liliana Villarraga de Ramírez (Universidad Nacional de Colombia, Facultad de Enfermería) en "Encuentro sobre promoción y prevención en salud mental en momentos de incertidumbre". Bogotá, 2020, julio 22.

6. Rodríguez A. (Asociación Colombiana de Facultades y Escuelas de Enfermería -ACOFAEN-). Conversación con: Liliana Villarraga de Ramírez (Universidad Nacional de Colombia, Facultad de Enfermería) en "Enfermeros en atención a personas infectadas por Covid 19". Bogotá, 2020, julio 29.

7. Mishel M. Uncertainity in illness. J Nurs Scholarsh 1988;20(4):225-231 DOI: https://doi.org/10.1111/j.1547-5069.1988. tb00082.x 